\title{
Tiny Cold Atmospheric Plasma Jet for Biomedical Applications
}

\author{
Zhitong Chen $*,+$, Richard Obenchain ${ }^{+}$(D) and Richard E. Wirz *(D) \\ Department of Mechanical and Aerospace Engineering, University of California, Los Angeles, CA 90095, USA; \\ robenchain@g.ucla.edu \\ * Correspondence: zhitongchen@ucla.edu (Z.C.); wirz@ucla.edu (R.E.W.) \\ † These authors contributed equally to this work.
}

check for

updates

Citation: Chen, Z.; Obenchain, R.; Wirz, R.E Tiny Cold Atmospheric

Plasma Jet for Biomedical

Applications. Processes 2021, 9, 249.

https://doi.org/10.3390/pr9020249

Academic Editor: Luisa A. Neves

Received: 8 January 2021

Accepted: 26 January 2021

Published: 29 January 2021

Publisher's Note: MDPI stays neutral with regard to jurisdictional claims in published maps and institutional affiliations.

Copyright: (c) 2021 by the authors. Licensee MDPI, Basel, Switzerland. This article is an open access article distributed under the terms and conditions of the Creative Commons Attribution (CC BY) license (https:// creativecommons.org/licenses/by/ $4.0 /)$.

\begin{abstract}
Conventional plasma jets for biomedical applications tend to have several drawbacks, such as high voltages, high gas delivery, large plasma probe volume, and the formation of discharge within the organ. Therefore, it is challenging to employ these jets inside a living organism's body. Thus, we developed a single-electrode tiny plasma jet and evaluated its use for clinical biomedical applications. We investigated the effect of voltage input and flow rate on the jet length and studied the physical parameters of the plasma jet, including discharge voltage, average gas and subject temperature, and optical emissions via spectroscopy (OES). The interactions between the tiny plasma jet and five subjects (de-ionized (DI) water, metal, cardboard, pork belly, and pork muscle) were studied at distances of $10 \mathrm{~mm}$ and $15 \mathrm{~mm}$ from the jet nozzle. The results showed that the tiny plasma jet caused no damage or burning of tissues, and the ROS/RNS (reactive oxygen/nitrogen species) intensity increased when the distance was lowered from $15 \mathrm{~mm}$ to $10 \mathrm{~mm}$. These initial observations establish the tiny plasma jet device as a potentially useful tool in clinical biomedical applications.
\end{abstract}

Keywords: cold atmospheric plasma; tiny plasma jet; biomedical applications

\section{Introduction}

Plasma is the fourth state of matter (solid, liquid, gas, and plasma), which is the most energetic and abundant state of matter, comprising over $99 \%$ of the universe's matter [1]. What makes the plasma unique is its gaseous combination of electrons, ions, and neutral species in both fundamental and excited states [2]. The properties of plasma change depending on the source and amount of energy supplied, and plasma is divided into thermal and non-thermal plasma according to the Maxwell-Boltzmann thermodynamic equilibrium [3]. Depending on the required application, there are a wide variety of plasmas generated under different conditions. Recently, cold atmospheric plasma devices (CAP) operating at atmospheric pressure and room temperature have exhibited great potential for biomedical applications [4-6]. Laroussi demonstrated that plasma generated at atmospheric pressure is a very effective sterilization agent in 1996 [7]. Isbary et al. proposed a first prospective randomized controlled trial to decrease bacterial load using CAP on chronic wounds in patients [8]. Pan et al. developed a novel method of tooth whitening employing CAP driven by direct current in atmospheric pressure air [9]. Chen et al. demonstrated a synergism between CAP and ICB (immune checkpoint blockade) integrated with microneedles to provide a platform technique for the treatment of cancer and other diseases in a minimally invasive manner [10]. More and more manuscripts have been published about CAP on sterilization/disinfection, wound healing, blood coagulation, oral health, cancer therapy, and other applications [11-17]. The efficiency of CAP for biomedical applications mainly relies on its many components, such as reactive nitrogen species (RNS) and reactive oxygen species (ROS) [18-20].

One of the aims of plasma biomedicine is to utilize CAP inside a living organism's body. The conventional form of CAP is not applicable for such in vivo biomedical applications, especially cancer therapy, due to major drawbacks, including high voltages, plasma jet 
volume, reactive species delivery, and the discharge formation within the organ [21]. To mitigate these problems, we developed a single-electrode tiny plasma jet device for biomedical applications. We then examined how different subjects, including deionized (DI) water, metal, cardboard, and tissue, affected the tiny plasma jet during jet-subject interaction processes.

\section{Experimental Section}

The single-electrode tiny plasma jet device (Figure 1) was developed at UCLA. It consisted of a powered needle electrode connected to a high voltage transformer, all contained within a 3D-printed polylactic acid (PLA) housing (TAZ 6 from LulzBot, Fargo, ND, USA). The electrode was powered by a tabletop DC power supply (1901B, B\&K Precision, Yorba Linda, CA, USA) at 8, 10, and 12 V. The DC-to-AC converter was built at UCLA, and a Chirk Industry transformer (RU3222, Chirk Industry, Taiwan) was used to step-up the voltage by $25 \times$ at a nominal frequency of $30 \mathrm{kHz}$. The input power of the tiny plasma jet was between 6 and $12 \mathrm{~W}$. The plastic (polycarbonate) nozzle had an inner diameter of $1.5 \mathrm{~mm}$ and a wall thickness of $0.5 \mathrm{~mm}$. Helium (He, ultra-high purity) was employed as feeding gas. The discharge voltage for the plasma jet was measured using a high voltage probe and oscilloscope.

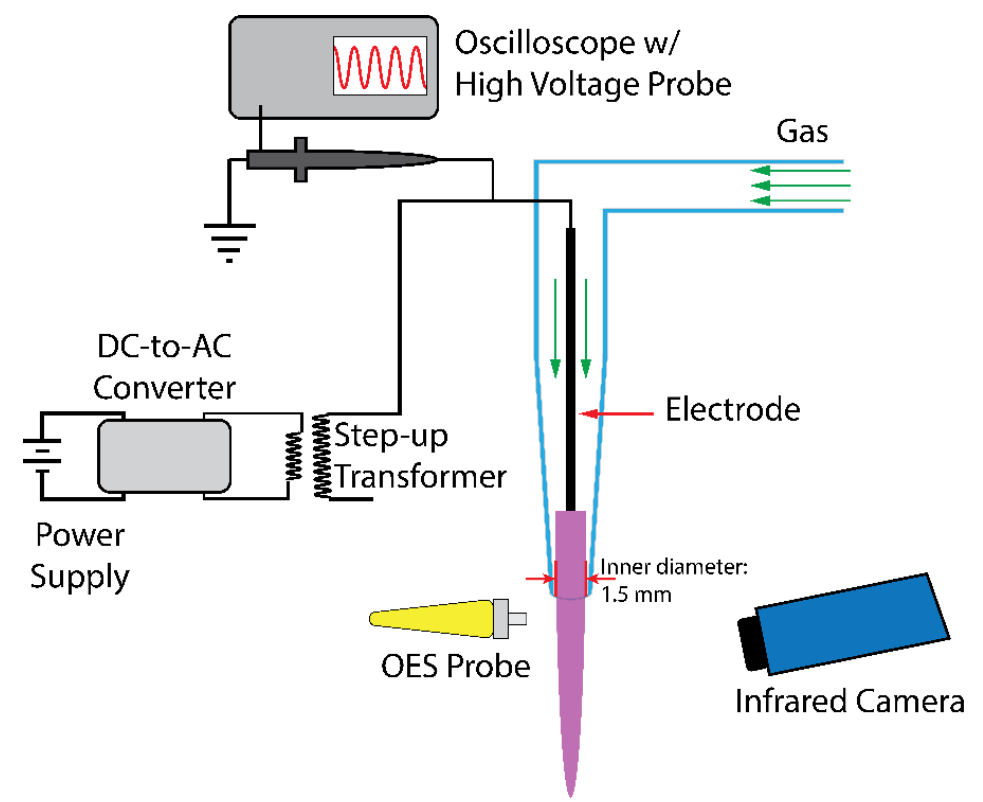

Figure 1. Schematic representation of the single electrode plasma jet device.

A fiber-coupled optical spectrometer (LR1, ASEQ Instruments, Vancouver, BC, Canada), with a range of wavelength 300-1000 nm, was employed to detect CAP-generated ROS and RNS (such as nitric oxide (NO), nitrogen cation $\left(\mathrm{N}_{2}{ }^{+}\right)$, atomic oxygen $(\mathrm{O})$, and hydroxyl radicals $(\bullet \mathrm{OH})$ ). The optical probe was placed at a radial distance of $10 \mathrm{~mm}$ from the center of the nozzle. Data were collected with an integration time of $600 \mathrm{~ms}$. All subjects but DI water were placed on non-conductive medical-grade plastic for treatment. DI water was placed within a standard plastic 6-cell culture plate.

Thermal measurements of the plasma jet alone and interacting with subjects were made with a long-wavelength infrared camera A655sc, FLIR Systems, Wilsonville, OR, USA) from a distance of approximately $15 \mathrm{~cm}$ diagonally above the subject; the relative position of the camera to the jet and subject remained consistent for all tests. Frame sequences for each time point consisted of a multi-second exposure recorded using Research IR 4.40 with individual frames extracted as needed after recording. A linear scale manually configured from $10{ }^{\circ} \mathrm{C}$ to $40{ }^{\circ} \mathrm{C}$ was selected for all images to allow for a sufficient dynamic range. 
Low-magnification optical images of tissue surfaces were made using a BW500 Digital Microscope. Other optical images were taken via digital SLR (D850, Nikon Corporation, Tokyo, Japan) using constant shutter speed, aperture, film speed, and relative position for all images.

\section{Results and Discussion}

Figure 2a shows the image of the single-electrode tiny plasma jet with a length of approximately $2.5 \mathrm{~cm}$ well collimated along the entire length. The thermal effects of the tiny plasma jet on its environment and subjects were measured via thermal camera (Figure $2 b$ ). The average gas temperature of the tiny plasma jet is around $25^{\circ} \mathrm{C}$, which is approximately equal to that of the local environment. Figure $2 \mathrm{c}$ shows the discharge voltage of the tiny plasma jet at $10 \mathrm{~V}$ input voltage and $3.02 \mathrm{~L} / \mathrm{min}$ He flow rate. The peak-peak discharge voltage is approximately $6.88 \mathrm{kV}$ with a frequency near $20 \mathrm{kHz}$. The electrode operates with sufficiently high frequency and voltage power to generate a strong electric field, resulting in the formation of the elongated plasma streamer by ionizing the surrounding gas atoms [22]. The magnitude of the current is in milliamperes. Figure $2 \mathrm{~d}$ shows the optical emission spectra of the tiny plasma jet. The identification of emission lines and bands was performed according to reference [23]. $\bullet \mathrm{OH}$ (hydroxyl radical) is present at $309 \mathrm{~nm}$. The He bands are assigned at 588, 668, and $705 \mathrm{~nm}$. The wavelength of 337, 376, and $381 \mathrm{~nm}$ could be indicative of the low-intensity $N_{2}$ second-positive system $\left(C^{3} \Pi_{\mathrm{u}}-\mathrm{B}^{3} \Pi_{\mathrm{g}}\right)$. Moreover, their magnitudes are at most a few thousandths of the highest peak $\mathrm{N}_{2}{ }^{+}(391 \mathrm{~nm})$, while 358 and $428 \mathrm{~nm}$ are also $\mathrm{N}_{2}{ }^{+}$. The composition of the tiny plasma jet is thus similar to conventional plasma jets $[24,25]$.
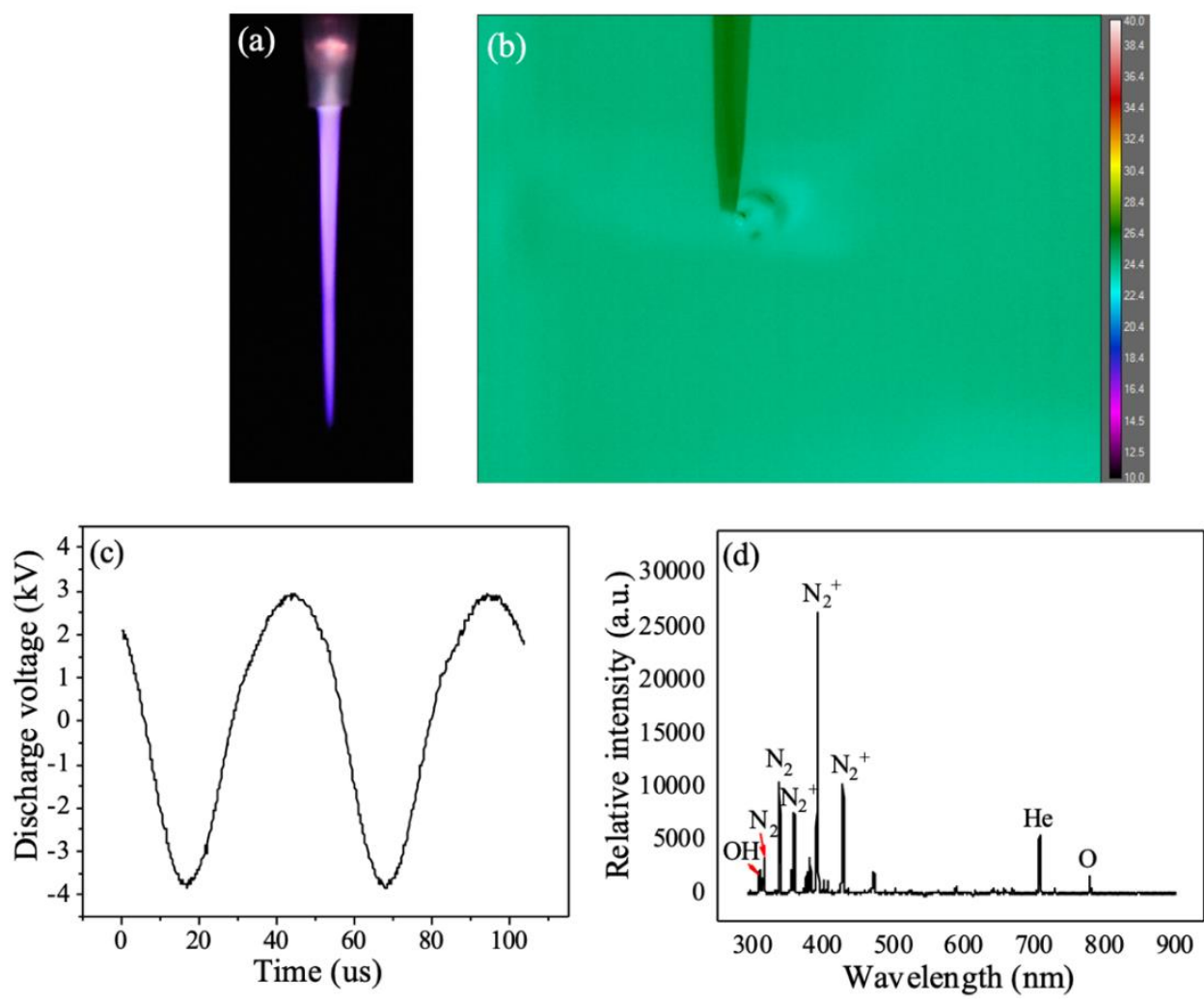

Figure 2. (a) Image of the tiny plasma jet and (b) thermal measurement of the vicinity of the tiny plasma jet. (c,d) represent the discharge voltage and optical emission spectrum of tiny plasma jet with input voltage at $10 \mathrm{~V}$ and $\mathrm{He}$ flow rate at $3.02 \mathrm{~L} / \mathrm{min}$, respectively.

Figure 3 shows the effect of input voltage and flow rate on the tiny plasma jet. In Figure $3 a$, the length of the plasma jet decreases when the flow rate increases at constant 
input voltage, while the length of the tiny plasma jet increases when the input voltage increases at a constant flow rate. We investigated the longest tiny plasma jet for each input voltage and found that the flow rate for the longest jet is $3.21 \mathrm{~L} / \mathrm{min}$ for $8 \mathrm{~V}, 3.02 \mathrm{~L} / \mathrm{min}$ for $10 \mathrm{~V}$, and $2.51 \mathrm{~L} / \mathrm{min}$ for $12 \mathrm{~V}$, respectively. Comparing the three longest plasma jets, input voltage plays a major role in affecting the length of the tiny plasma jet. As expected, the flow rate has almost no effect on the peak-peak discharge voltage in Figure 3c; the longest jets for each input have been marked in an ellipse. The authors also pointed out that input voltage plays a significant effect on the length of the plasma plume, among other factors, including flow rate and the diameter of the nozzle exit [26]. The upstream region discharge affects the stability and length of the downstream plasma jet [27]. We used the tiny plasma jet at $10 \mathrm{~V}$ input voltage and $3.02 \mathrm{~L} / \mathrm{min}$ for the following measurements.

(a)

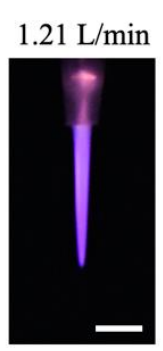

$12 \mathrm{~V}$
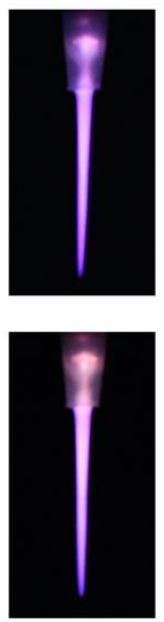
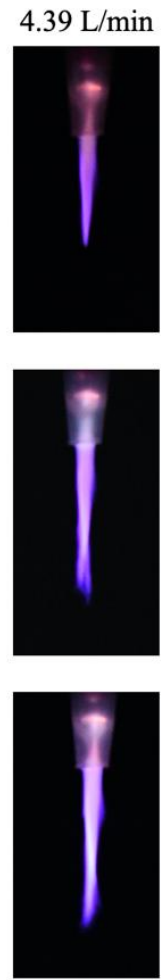
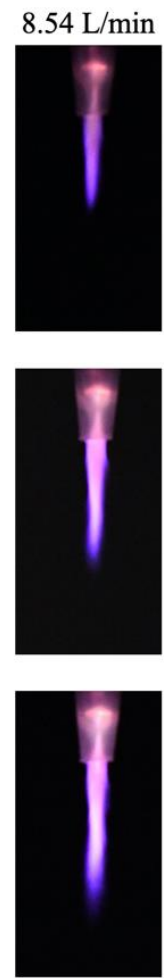

(b)

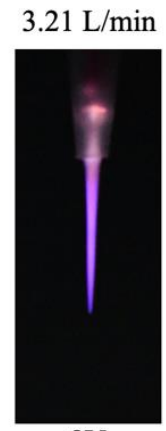

8V

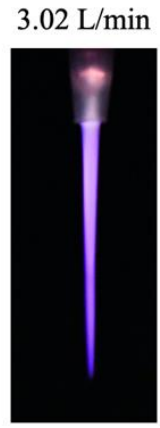

$10 \mathrm{~V}$

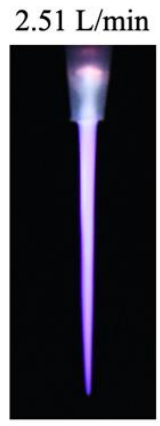

$12 \mathrm{~V}$ (c)

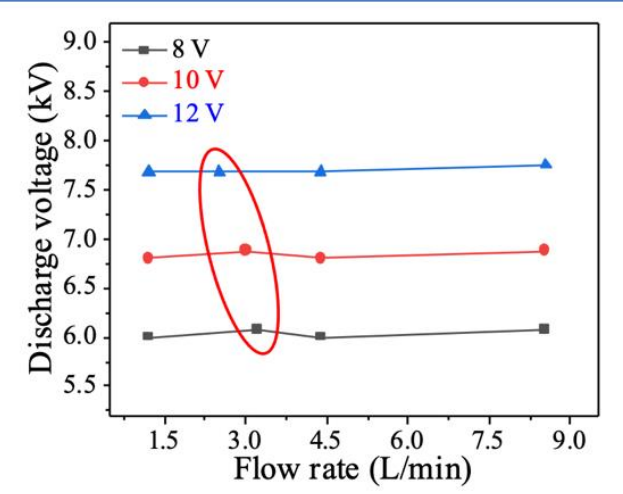

Figure 3. (a) The effect of flow rate $(1.21 \mathrm{~L} / \mathrm{min}, 4.39 \mathrm{~L} / \mathrm{min}$, and $8.54 \mathrm{~L} / \mathrm{min})$ and input voltage $(8 \mathrm{~V}, 10 \mathrm{~V}$, and $12 \mathrm{~V})$ on the length of the tiny plasma jet. (b) The longest tiny plasma jet for $8 \mathrm{~V}, 10 \mathrm{~V}$, and $12 \mathrm{~V}$ input. (c) The peak-peak discharge voltage for the tiny plasma jet at a different He flow rate. Scale bar: $5 \mathrm{~mm}$.

Water is the main component of many living things, exemplified by blood being primarily composed of water [28]. Therefore, it is necessary to study the effect of water on the tiny plasma jet for future biomedical applications. In addition, the conductivity of subjects cannot be controlled during the use of the tiny plasma jet for the treatment of diseases. Here, we selected an aluminum cutout and length of cardboard as conductive and non-conductive subjects, respectively. Figure 4a shows images of the tiny plasma jet interacting with DI water, metal, and cardboard at $10 \mathrm{~mm}$ and $15 \mathrm{~mm}$ distances. Compared with the tiny plasma alone, the peak-peak discharge voltages of the jet interacting with DI water, metal, and cardboard decrease slightly at the $15 \mathrm{~mm}$ distance, while the peak-peak discharge voltage decreases more for each one at $10 \mathrm{~mm}$ distance compared with $15 \mathrm{~mm}$. From a $15 \mathrm{~mm}$ distance to $10 \mathrm{~mm}$, plasma intensity increases, especially for DI water and metal, becoming visibly brighter. Figure $4 \mathrm{~b}$ shows the optical emission spectra of the tiny plasma jet interacting with DI water, metal, and cardboard at $10 \mathrm{~mm}$ and $15 \mathrm{~mm}$ distances. At a $15 \mathrm{~mm}$ distance, the ROS/RNS intensity of the tiny plasma jet interacting with DI water, 
metal, and cardboard only varies slightly when compared with the tiny plasma jet operating without a subject. From $15 \mathrm{~mm}$ to $10 \mathrm{~mm}$, the ROS/RNS intensity increases slightly for jet-cardboard interaction, around $50 \%$ for jet-metal interaction, and approximately $200 \%$ for jet-DI water interaction, respectively. This change in optical emissions spectrometry (OES) intensity for DI water and metal, but not cardboard, implies a change in the plasma plume characteristics when certain subjects are placed nearer to the nozzle opening, likely related to the electrical conductivity of the subjects. While DI water is non-conductive itself, it becomes conductive after plasma treatment [29]. Thus, DI water and metal as conductive subjects result in higher plasma intensity than the cardboard as a non-conductive subject. Plasma interacting with DI water will generate ROS/RNS, such as hydrogen peroxide, nitrite, and other species, in the water to form a plasma solution. In our previous papers, we indicated that the concentration of ROS/RNS depends on the discharge voltage/current, types of feeding gas, feeding gas flow rate, water volume, and other parameters $[3,19,25,29]$. For the same parameters, the concentration of ROS/RNS in water exhibits time-dependent behavior. In addition, the $\mathrm{pH}$ of the plasma solution will increase with the increasing time of plasma-water interaction [14]. Interaction between the tiny plasma jet and the metal surface may bias the surface positively and, in addition to standard fluid motion, cause the discharge to spread out horizontally along the metal's surface further than with other materials. At the interaction between the plasma jet and DI water, the pressure from the plasma flow creates a small pocket in the water's surface, potentially modifying the local airflow to reduce the dispersion of reactive species along the surface; along with the tendency of jet/water interactions to increase reactive species generation, this discharge counterflow may help to increase species density near the emission tip. This may explain why the OES intensity of the jet interacting with DI water is measured as higher than when interacting with metal. Gerling et al. indicated that the distance between the electrode and the ground is significant in generating different plasma behaviors, with a "pre-bullet" being generated at a $15 \mathrm{~mm}$ gap but no "pre-bullet" at $10 \mathrm{~mm}$ [30]. Since we're using a single electrode in this situation, the subject might be considered a floating electrode and, for the $15 \mathrm{~mm}$ gap, what we might be seeing is the incomplete discharge for the pre-bullet, resulting in the decreased OES intensities. Nastuta et al. tested atmospheric pressure at the plasma jet-living tissue interface at $5 \mathrm{~mm}$ and $15 \mathrm{~mm}$ and found similar drops in intensity for subjects [31].

Figure 5a shows images of the tiny plasma jet interacting with pork belly and muscle at $10 \mathrm{~mm}$ and $15 \mathrm{~mm}$ distance. From $15 \mathrm{~mm}$ to $10 \mathrm{~mm}$, the plasma intensity at both subjects increase, and the OES results in Figure $5 \mathrm{~b}$ also confirm this. Comparing OES results for belly and muscle at $15 \mathrm{~mm}$ distance with the tiny plasma jet alone, there is minimal change in ROS/RNS intensity, while ROS/RNS intensity largely increases when the distance is reduced from $15 \mathrm{~mm}$ to $10 \mathrm{~mm}$. In addition, ROS/RNS intensity of jet-muscle interaction increases more than jet-belly interaction at the $10 \mathrm{~mm}$ distance. Figure $5 \mathrm{c}$ shows highresolution images of pork belly and muscle before and after 2 min tiny plasma treatment at $10 \mathrm{~mm}$ and $15 \mathrm{~mm}$ distance. There is no damage or burning on belly and muscle surfaces after $2 \mathrm{~min}$ treatment at $10 \mathrm{~mm}$ and $15 \mathrm{~mm}$. We tried to reduce the distance and increase other inputs to see the effect on biological tissues. The results show no damage to tissues. The reason might be that lower input power is too low to damage tissues. Figure 6 exhibits thermal images of the tiny plasma jet interacting with five subjects after $2 \mathrm{~min}$ at $10 \mathrm{~mm}$ and $15 \mathrm{~mm}$. For cardboard and DI water, the center temperatures of the interacting area decrease from $15 \mathrm{~mm}$ to $10 \mathrm{~mm}$; however, the variations are small $\left(0.6{ }^{\circ} \mathrm{C}\right.$ and $0.5^{\circ} \mathrm{C}$, respectively) and may be considered noise. Due to jet flow, indentations form on the water surface at both distances, which may partly explain why ROS/RNS intensities are higher than with other subjects. For metal, belly, and muscle, the center temperature after $2 \mathrm{~min}$ interaction increases when the distance is changed from $15 \mathrm{~mm}$ to $10 \mathrm{~mm}$ (increases of $2.2^{\circ} \mathrm{C}, 3.0^{\circ} \mathrm{C}$, and $6.6^{\circ} \mathrm{C}$, respectively), but it still remains at a comfortable temperature for human beings. The belly and muscle samples, in particular, begin at significantly cooler temperatures, and the interaction with the gas alone from the jet would be expected to 
increase the temperature of the target area to room temperature, as can be seen in the larger outer thermal "rings" in Figure 6, which are near-universal in size and temperature between non-liquid subjects; the more relevant interaction with the plasma discharge for the belly and muscle samples can be identified by the central thermal hotspots. Thus, the tiny plasma jet should be an ideal and safe tool for in vivo biomedical applications.

(a)

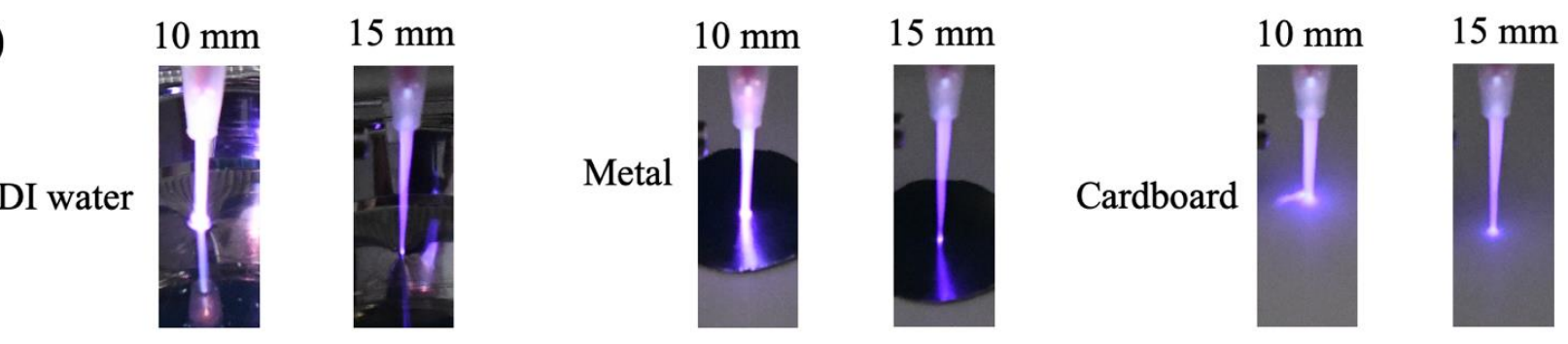

(b)
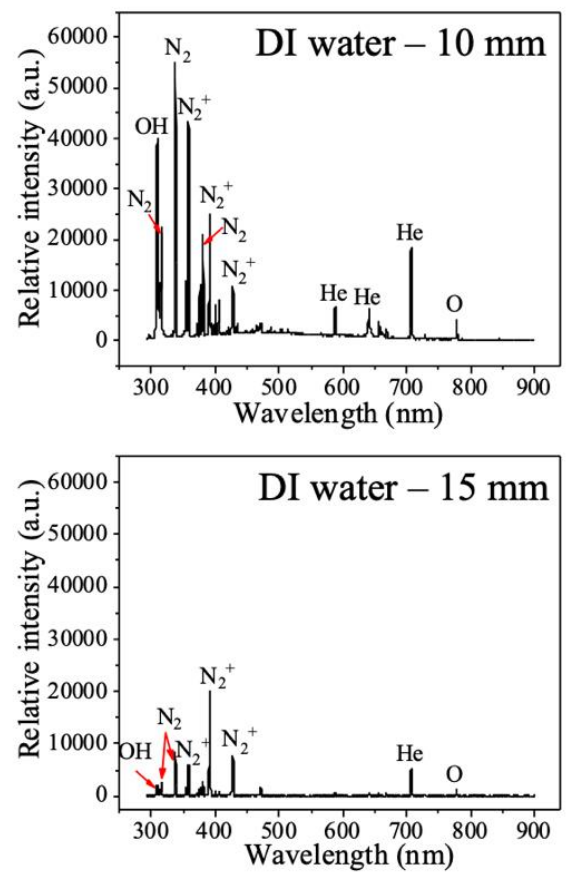
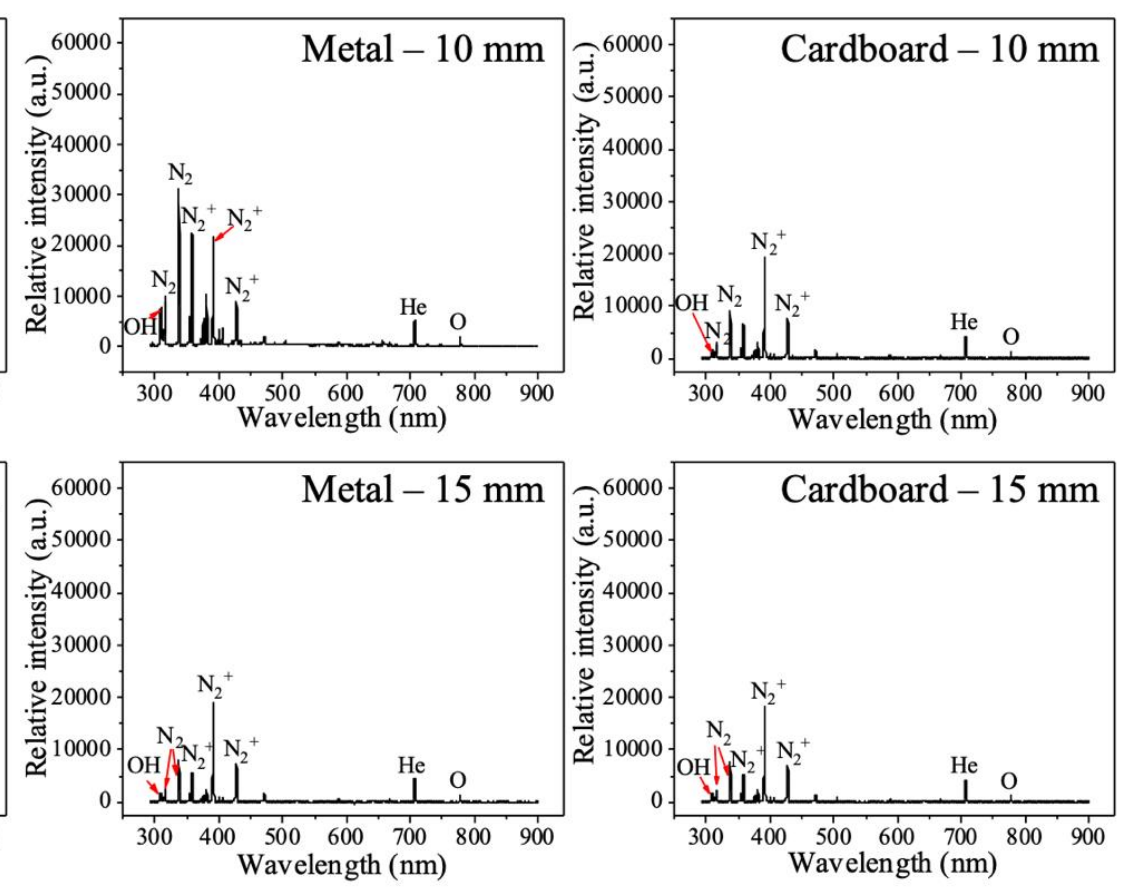

Figure 4. (a) Images of the tiny plasma jet interacting with deionized (DI) water, metal, and cardboard at $10 \mathrm{~mm}$ and $15 \mathrm{~mm}$ distance. (b) The effect of interacting processes between jets and subjects (DI water, metal, and cardboard) on optical emission spectra of tiny plasma jets.

Cold plasma has received considerable attention for its potential biomedical applications, including blood coagulation, wound healing, sterilization/inactivation, skin regeneration, oral health, and cancer therapy $[4,32,33]$. The efficiency of plasma for biomedical applications mainly relies on the ROS/RNS generated in it [34,35]. As shown in Figures $2 \mathrm{~d}, 4 \mathrm{~b}$ and $5 \mathrm{~b}$, the tiny plasma jet is an ideal ROS/RNS source, and ROS/RNS intensity increases when the plasma jet is used nearer to tissues and conductive materials. This single-electrode tiny plasma jet without the major drawbacks of conventional plasma jet (high voltage, high flow rate, reactive species delivery, plasma jet volume, and discharge formation in the organ) will have more potential biomedical applications, especially for in vivo clinical applications. For example, plasma disinfects bacteria in the oral cavity, such as Enterococcus faecalis and Candida albicans [36,37]. This reliable and user-friendly tiny plasma jet could be directed manually to target a root canal for disinfection. A tiny plasma jet is also an ideal tool when applied inside a living body, especially for cancer therapy. We take a glioblastoma, for example, which is a highly malignant aggressive neoplasm 
with rapid growth and resistance to all current therapies [38,39]. Our previous results have shown that plasma is effective at preventing glioblastoma growth in the mouse brain [40]. The tiny plasma jet, with a low flow rate and limited discharge voltage, can be generated in closer proximity to the organ, safely delivering ROS/RNS across the blood-brain barrier to the tumor. Overall, the tiny plasma jet is useful and should be considered in clinical medical applications. A further understanding of the precise underlying mechanisms will provide the 'best' combination when employed as a treatment strategy.

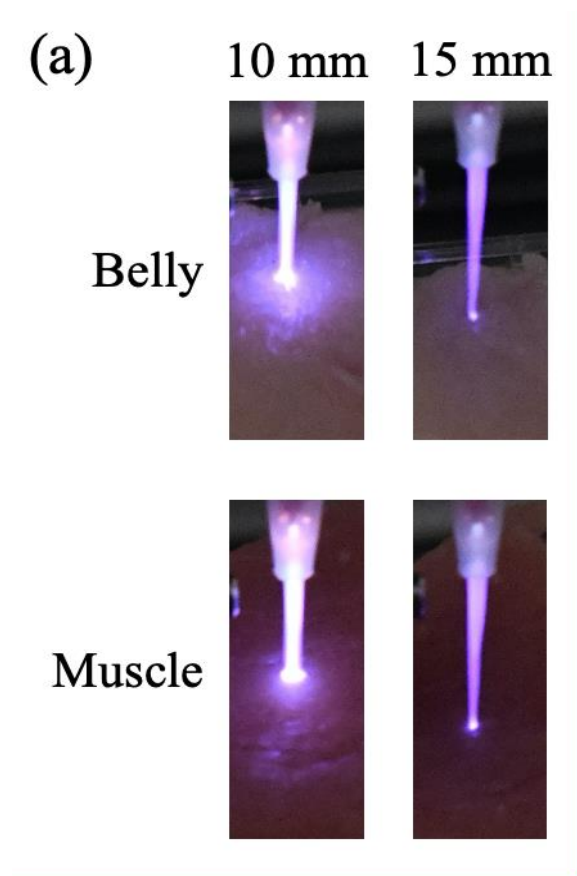

(b)
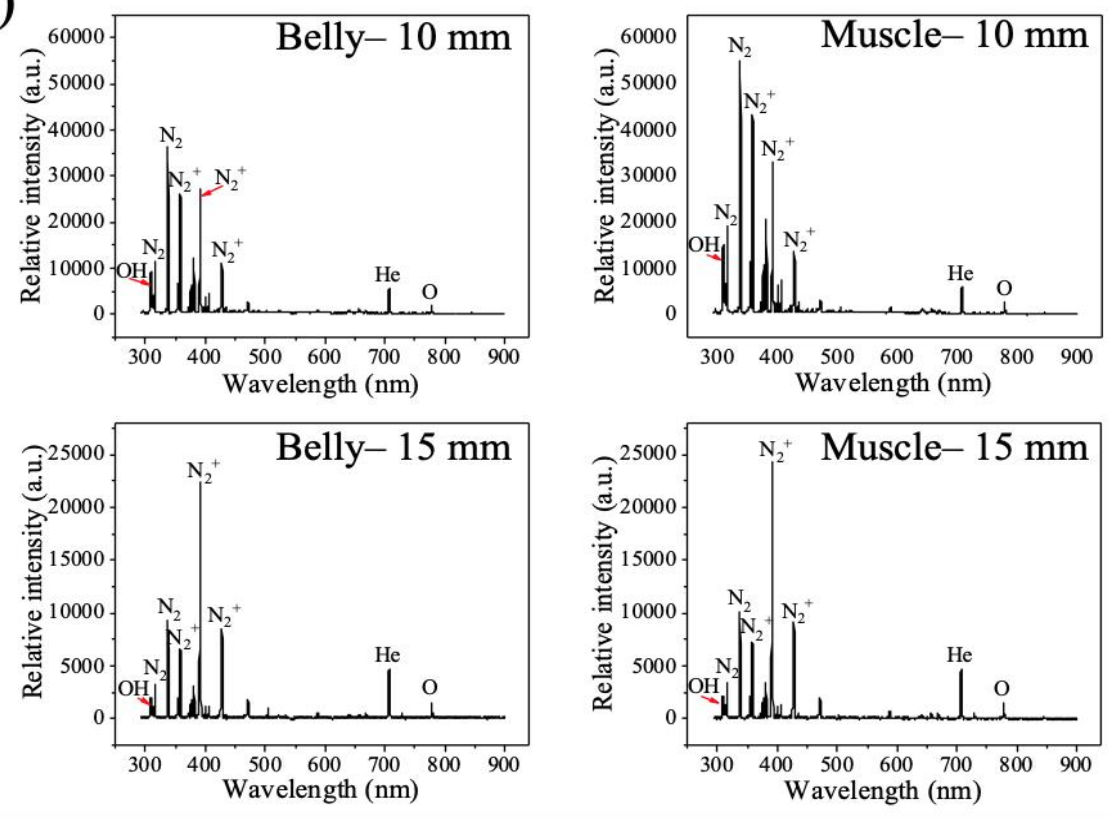

(c)

Belly
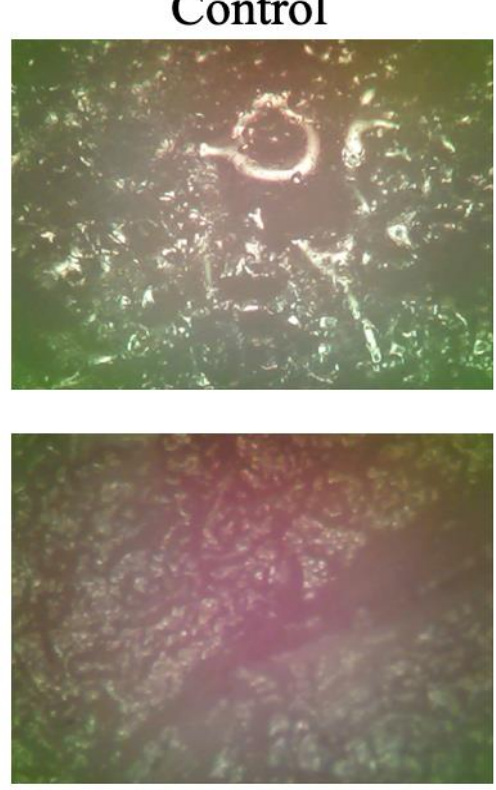

$10 \mathrm{~mm}$
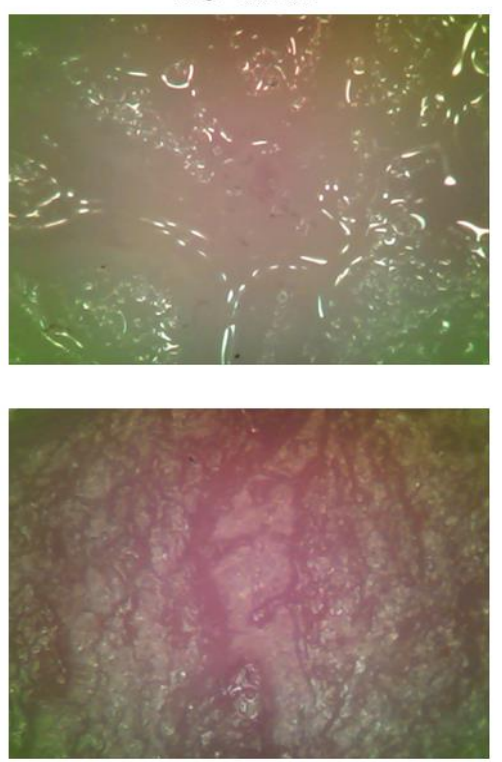

$15 \mathrm{~mm}$
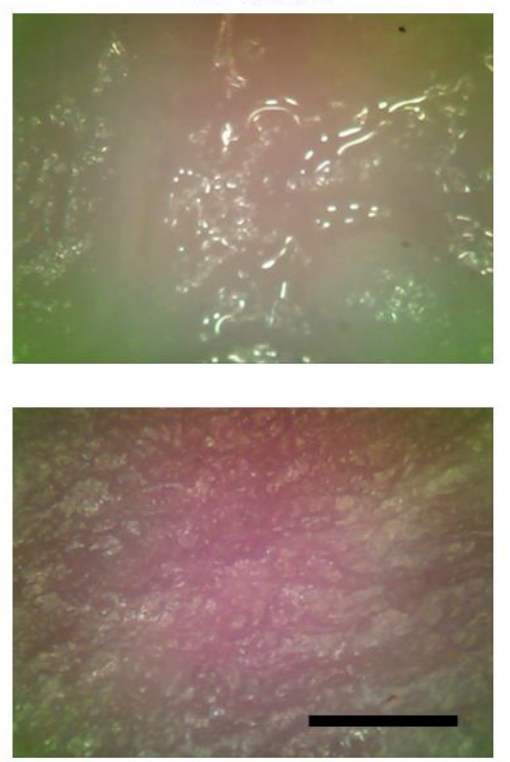

Figure 5. (a) Images of tiny plasma jet interacting with pork belly and muscle at $10 \mathrm{~mm}$ and $15 \mathrm{~mm}$ distance. (b) The effect of interacting processes between jets and pork (belly and muscle) on optical emission spectra of tiny plasma jets. (c) The surface images of pork (belly and muscle) after jet-pork interactions for control (0 min), $10 \mathrm{~mm}$ (2 min), and $15 \mathrm{~mm}$ (2 min). Tissue surface measurements were made using a BW500 Digital Microscope to examine the surface of each sample. Scale bar: $1 \mathrm{~mm}$. 


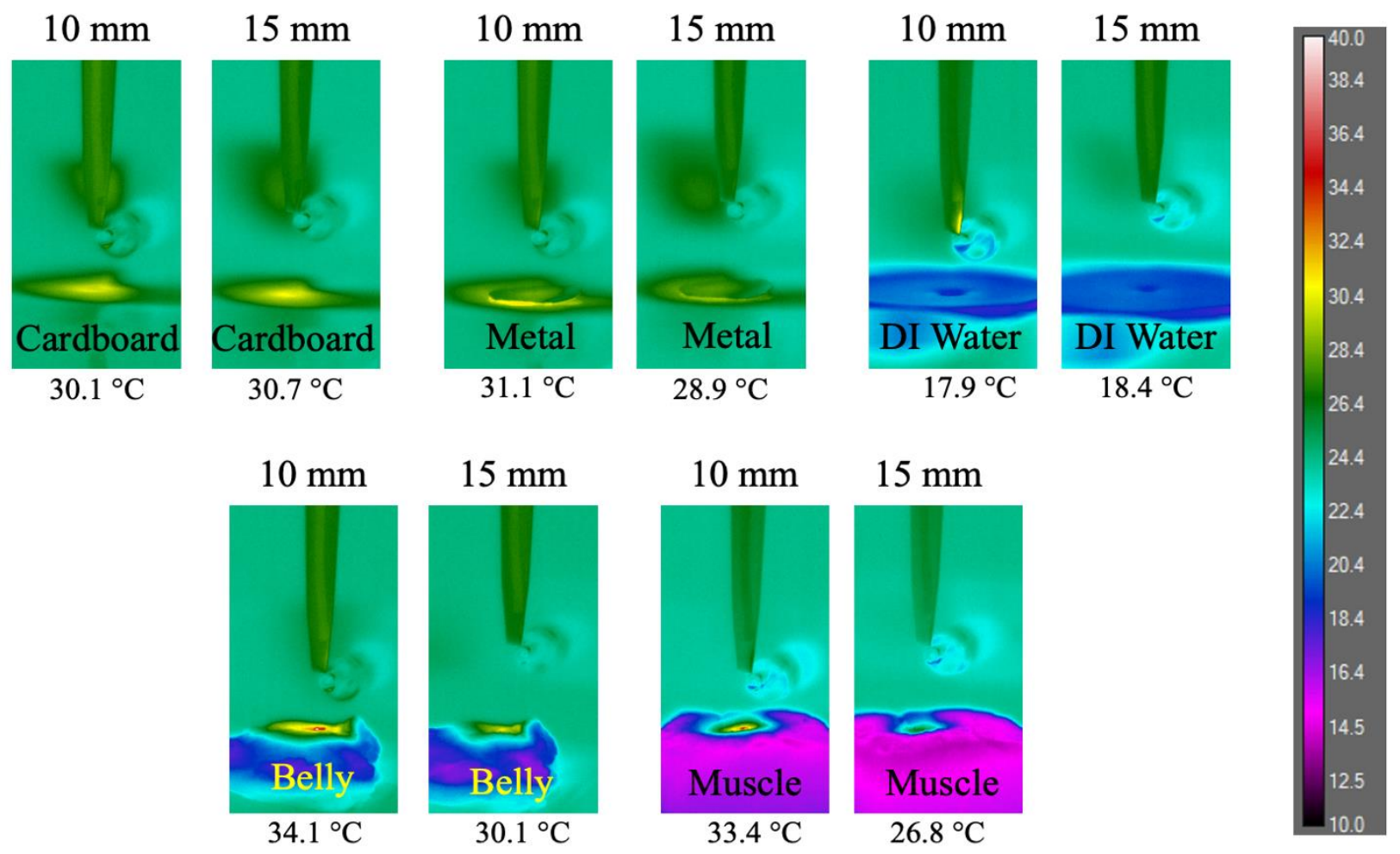

Figure 6. Thermal measurement of the tiny plasma jet interacting with cardboard, metal, DI water, belly, and muscle for $2 \mathrm{~min}$ at $10 \mathrm{~mm}$ and $15 \mathrm{~mm}$ distances. The temperature marked below each image is the center temperature of a tiny plasma jet interacting with subjects.

\section{Conclusions}

In summary, we developed a single-electrode tiny plasma device and investigated its physics and interactions with five subjects (DI water, metal, cardboard, belly, and muscle) at $10 \mathrm{~mm}$ and $15 \mathrm{~mm}$. For non-conductive subjects, ROS/RNS intensity shows very little change when the distance is decreased from $15 \mathrm{~mm}$ to $10 \mathrm{~mm}$, while ROS/RNS intensity increases for conductive subjects with distance decreasing from $15 \mathrm{~mm}$ to $10 \mathrm{~mm}$, especially for the muscle. For five subjects, the center temperature of jet-subjects interaction still remains in the comfortable temperature range for human beings after 2 min interaction for both $10 \mathrm{~mm}$ and $15 \mathrm{~mm}$ distances. High-resolution images of belly and pork after $2 \mathrm{~min}$ tiny plasma treatment show no damage or burning on tissues' surfaces. The results of this study are preliminary research for employing the tiny plasma jet in clinical biomedical applications in the future.

Author Contributions: Z.C. and R.O.: Conceptualization, methodology, experiments, formal analysis, resources, project administration, writing; R.E.W.: Conceptualization, methodology, project administration, writing. All authors have read and agreed to the published version of the manuscript.

Funding: This work was supported by the UCLA Plasma and Space Propulsion Laboratory.

Institutional Review Board Statement: Not Applicable.

Informed Consent Statement: Not Applicable.

Data Availability Statement: The data that support the findings of this study are available from the corresponding author upon reasonable request.

Conflicts of Interest: The authors declare no conflict of interest. 


\section{References}

1. Morozov, A.I. Introduction to Plasma Dynamics; CRC Press: Boca Raton, FL, USA, 2012.

2. Lu, X.; Naidis, G.; Laroussi, M.; Reuter, S.; Graves, D.; Ostrikov, K. Reactive species in non-equilibrium atmospheric-pressure plasmas: Generation, transport, and biological effects. Phys. Rep. 2016, 630, 1. [CrossRef]

3. Chen, Z. Development of New Cold Atmospheric Plasma Devices and Approaches for Cancer Treatment. Ph.D. Thesis, The George Washington University, Washington, DC, USA, 2018.

4. Fridman, G.; Gutsol, A.; Shekhter, A.B.; Vasilets, V.N.; Fridman, A. Applied Plasma Medicine. Plasma Process. Polym. 2008, 5, 503. [CrossRef]

5. Li, W.; Yu, H.; Ding, D.; Chen, Z.; Wang, Y.; Wang, S.; Li, X.; Keidar, M.; Zhang, W. Cold atmospheric plasma and iron oxide-based magnetic nanoparticles for synergetic lung cancer therapy. Free Radic. Biol. Med. 2019, 130, 71. [CrossRef] [PubMed]

6. Kong, M.G.; Kroesen, G.; Morfill, G.; Nosenko, T.; Shimizu, T.; van Dijk, J.; Zimmermann, J. Plasma medicine: An introductory review. New J. Phys. 2009, 11, 115012. [CrossRef]

7. Laroussi, M. Sterilization of contaminated matter with an atmospheric pressure plasma. IEEE Trans. Plasma Sci. 1996, 24, 1188. [CrossRef]

8. Isbary, G.; Morfill, G.; Schmidt, H.; Georgi, M.; Ramrath, K.; Heinlin, J.; Karrer, S.; Landthaler, M.; Shimizu, T.; Steffes, B. A first prospective randomized controlled trial to decrease bacterial load using cold atmospheric argon plasma on chronic wounds in patients. Br. J. Dermatol. 2010, 163, 78.

9. Pan, J.; Sun, P.; Tian, Y.; Zhou, H.; Wu, H.; Bai, N.; Liu, F.; Zhu, W.; Zhang, J.; Becker, K.H. A novel method of tooth whitening using cold plasma microjet driven by direct current in atmospheric-pressure air. IEEE Trans. Plasma Sci. 2010, 38, 3143. [CrossRef]

10. Chen, G.; Chen, Z.; Wen, D.; Wang, Z.; Li, H.; Zeng, Y.; Dotti, G.; Wirz, R.E.; Gu, Z. Transdermal cold atmospheric plasma-mediated immune checkpoint blockade therapy. Proc. Natl. Acad. Sci. USA 2020, 117, 3687. [CrossRef]

11. Joshi, S.G.; Cooper, M.; Yost, A.; Paff, M.; Ercan, U.K.; Fridman, G.; Friedman, G.; Fridman, A.; Brooks, A.D. Nonthermal dielectric-barrier discharge plasma-induced inactivation involves oxidative DNA damage and membrane lipid peroxidation in Escherichia coli. Antimicrob. Agents Chemother. 2011, 55, 1053. [CrossRef]

12. Schmidt, A.; Bekeschus, S.; Wende, K.; Vollmar, B.; von Woedtke, T. A cold plasma jet accelerates wound healing in a murine model of full-thickness skin wounds. Exp. Dermatol. 2017, 26, 156.

13. Keping, Y.; Qikang, J.; Zheng, C.; Guanlei, D.; Shengyong, Y.; Zhen, L. Pulsed cold plasma-induced blood coagulation and its pilot application in stanching bleeding during rat hepatectomy. Plasma Sci. Technol. 2018, 20, 044005.

14. Chen, Z.; Lin, L.; Cheng, X.; Gjika, E.; Keidar, M. Effects of cold atmospheric plasma generated in deionized water in cell cancer therapy. Plasma Process. Polym. 2016, 13, 1151. [CrossRef]

15. Khlyustova, A.; Labay, C.; Machala, Z.; Ginebra, M.-P.; Canal, C. Important parameters in plasma jets for the production of RONS in liquids for plasma medicine: A brief review. Front. Chem. Sci. Eng. 2019, 13, 238. [CrossRef]

16. Chen, Z.; Garcia, G., Jr.; Arumugaswami, V.; Wirz, R.E. Cold atmospheric plasma for SARS-CoV-2 inactivation. Phys. Fluids 2020, 32, 111702. [CrossRef] [PubMed]

17. Chen, Z.; Xu, R.-G.; Chen, P.; Wang, Q. Potential Agricultural and Biomedical Applications of Cold Atmospheric Plasma-Activated Liquids with Self-Organized Patterns Formed at the Interface. IEEE Trans. Plasma Sci. 2020, 48, 3455. [CrossRef]

18. Graves, D.B. The emerging role of reactive oxygen and nitrogen species in redox biology and some implications for plasma applications to medicine and biology. J. Phys. D Appl. Phys. 2012, 45, 263001. [CrossRef]

19. Chen, Z.; Cheng, X.; Lin, L.; Keidar, M. Cold atmospheric plasma discharged in water and its potential use in cancer therapy. J. Phys. D Appl. Phys. 2016, 50, 015208. [CrossRef]

20. Xu, R.-G.; Chen, Z.; Keidar, M.; Leng, Y. The impact of radicals in cold atmospheric plasma on the structural modification of gap junction: A reactive molecular dynamics study. Int. J. Smart Nano Mater. 2019, 10, 144. [CrossRef]

21. Mirpour, S.; Piroozmand, S.; Soleimani, N.; Faharani, N.J.; Ghomi, H.; Eskandari, H.F.; Sharifi, A.M.; Mirpour, S.; Eftekhari, M.; Nikkhah, M. Utilizing the micron sized non-thermal atmospheric pressure plasma inside the animal body for the tumor treatment application. Sci. Rep. 2016, 6, 29048. [CrossRef]

22. Shashurin, A.; Keidar, M. Experimental approaches for studying non-equilibrium atmospheric plasma jets. Phys. Plasmas 2015, 22, 122002. [CrossRef]

23. Pearse, R.W.B.; Gaydon, A.G. Identification of Molecular Spectra; Chapman and Hall: Boca Raton, FL, USA, 1976.

24. Cheng, X.; Sherman, J.; Murphy, W.; Ratovitski, E.; Canady, J.; Keidar, M. The Effect of Tuning Cold Plasma Composition on Glioblastoma Cell Viability. PLoS ONE 2014, 9, e98652. [CrossRef] [PubMed]

25. Chen, Z.; Lin, L.; Cheng, X.; Gjika, E.; Keidar, M. Treatment of gastric cancer cells with nonthermal atmospheric plasma generated in water. Biointerphases 2016, 11, 031010. [CrossRef] [PubMed]

26. Xiong, Q.; Lu, X.; Ostrikov, K.; Xiong, Z.; Xian, Y.; Zhou, F.; Zou, C.; Hu, J.; Gong, W.; Jiang, Z. Length control of He atmospheric plasma jet plumes: Effects of discharge parameters and ambient air. Phys. Plasmas 2009, 16, 043505. [CrossRef]

27. Li, Q.; Li, J.-T.; Zhu, W.-C.; Zhu, X.-M.; Pu, Y.-K. Effects of gas flow rate on the length of atmospheric pressure nonequilibrium plasma jets. Appl. Phys. Lett. 2009, 95, 141502. [CrossRef]

28. Lu, X.; Keidar, M.; Laroussi, M.; Choi, E.; Szili, E.; Ostrikov, K. Transcutaneous plasma stress: From soft-matter models to living tissues. Mater. Sci. Eng. R Rep. 2019, 138, 36. [CrossRef] 
29. Chen, Z.; Zhang, S.; Levchenko, I.; Beilis, I.I.; Keidar, M. In vitro demonstration of cancer inhibiting properties from stratified self-organized plasma-liquid interface. Sci. Rep. 2017, 7, 12163. [CrossRef] [PubMed]

30. Gerling, T.; Nastuta, A.; Bussiahn, R.; Kindel, E.; Weltmann, K. Back and forth directed plasma bullets in a helium atmospheric pressure needle-to-plane discharge with oxygen admixtures. Plasma Sour. Sci. Technol. 2012, 21, 034012. [CrossRef]

31. Nastuta, V.; Pohoata, V.; Topala, I. Atmospheric pressure plasma jet-Living tissue interface: Electrical, optical, and spectral characterization. J. Appl. Phys. 2013, 113, 183302. [CrossRef]

32. Babaeva, N.Y.; Naidis, G.V. Modeling of plasmas for biomedicine. Trends Biotechnol. 2018, 36, 603. [CrossRef]

33. Laroussi, M.; Lu, X.; Keidar, M. Perspective: The physics, diagnostics, and applications of atmospheric pressure low temperature plasma sources used in plasma medicine. J. Appl. Phys. 2017, 122, 020901.

34. Labay, C.; Roldán, M.; Tampieri, F.; Stancampiano, A.; Bocanegra, P.E.; Ginebra, M.-P.; Canal, C. Enhanced Generation of Reactive Species by Cold Plasma in Gelatin Solutions for Selective Cancer Cell Death. ACS Appl. Mater. Interfaces 2020, 12, 47256-47269. [CrossRef] [PubMed]

35. Szili, E.J.; Hong, S.-H.; Oh, J.-S.; Gaur, N.; Short, R.D. Tracking the penetration of plasma reactive species in tissue models. Trends Biotechnol. 2018, 36, 594. [CrossRef] [PubMed]

36. Lu, X.; Cao, Y.; Yang, P.; Xiong, Q.; Xiong, Z.; Xian, Y.; Pan, Y. An RC Plasma Device for Sterilization of Root Canal of Teeth. IEEE Trans. Plasma Sci. 2009, 37, 668.

37. Kerlikowski, A.; Matthes, R.; Pink, C.; Steffen, H.; Schlüter, R.; Holtfreter, B.; Weltmann, K.D.; von Woedtke, T.; Kocher, T.; Jablonowski, L. Effects of cold atmospheric pressure plasma and disinfecting agents on Candida albicans in root canals of extracted human teeth. J. Biophotonics 2020,13, e202000221. [CrossRef]

38. Lim, M.; Xia, Y.; Bettegowda, C.; Weller, M. Current state of immunotherapy for glioblastoma. Nat. Rev. Clin. Oncol. 2018, 15, 422. [CrossRef]

39. Wick, W.; Gorlia, T.; Bendszus, M.; Taphoorn, M.; Sahm, F.; Harting, I.; Brandes, A.A.; Taal, W.; Domont, J.; Idbaih, A. Lomustine and bevacizumab in progressive glioblastoma. N. Engl. J. Med. 2017, 377, 1954. [CrossRef]

40. Chen, Z.; Simonyan, H.; Cheng, X.; Gjika, E.; Lin, L.; Canady, J.; Sherman, J.H.; Young, C.; Keidar, M. A novel micro cold atmospheric plasma device for glioblastoma both in vitro and in vivo. Cancers 2017, 9, 61. [CrossRef] 